\title{
G. Gêcoconerões
}

\section{Imagens da Modernidade: a fotografia como reveladora de sentidos, contextos e práticas sociais da vida moderna}

\author{
SANTOS, Maynara Andrielly Silva ${ }^{1}$ \\ LEITE, Pedro de Farias ${ }^{2}$
}

\begin{abstract}
Recebido (Received): 14/04/2021 Aceito (Accepted): 25/05/2021
Como citar este artigo: SANTOS, M.A.S; LEITE, P. de. F. Imagens da modernidade: a fotografía como reveladora de sentidos, contextos e práticas sociais da vida moderna Geoconexões (online), v.1, n.1, p. 36-55, 2021.
\end{abstract}

RESUMO: Em busca de evidenciar a importância das imagens enquanto fonte documental na pesquisa historiográfica, os autores deste trabalho fazem uma retomada histórica acerca das origens da fotografia e seu processo de incorporação à historiografia, assim como percorrem brevemente a dinâmica entre os estudos teórico-metodológico acerca das possibilidades de uso das imagens na construção do saber Histórico. Ao utilizar as imagens dentro de recortes espaço-temporais específicos, exploram na prática a função das imagens para a análise de situações histórico-concretas a fim de revelar/identificar a realidade que as informa através do completo afastamento de uma concepção metodista das fontes documentais, que apesar de ter-se atido precisamente às fontes oficiais escritas no século XIX ainda tem permanências nas interpretações historiográficas da contemporaneidade, refletindo-se também no uso das imagens que, para muitos, "refletem a realidade em si" devido ao seu caráter visual. $\mathrm{Na}$ tentativa de revelar sentidos, contextos, valores e/ou práticas sociais, as imagens aqui foram utilizadas em complementariedade com a teoria, que faz a análise concreta de situações sociais (também) concretas - evidenciando, assim, a importância das fontes visuais/imagéticas/fotográficas no desenvolvimento do saber histórico.

PALAVRAS CHAVES: historiografia, imagens, fontes visuais.

\section{IMAGES OF MODERNITY: PHOTOGRAPHY AS A REVEALER OF MEANINGS, CONTEXTS AND SOCIAL PRACTICES OF MODERN LIFE}

\begin{abstract}
In order to highlight the importance of images as documental source in the historiographical research, the authors of this work make a historical retake on the origins of photography and its process of incorporation into historiography, as well as briefly review the dynamics between theoretical-methodological studies about the possibilities of using images in the construction of Historical knowledge. By using the images within specific spatio-temporal cuts, they explore in practice the role of images for the analysis of concrete historical situations in order to reveal/identify the reality that informs them through the complete departure from a Methodist conception of documentary sources, that despite having adhered precisely to official sources written in the 19th century, there are still permanencies in contemporary historiographical interpretations, which is also reflected in the use of images that, for many, "reflect reality itself" due to its character visual. In an attempt to reveal meanings, contexts, values and/or social practices, the images here were used in complementarity with the theory, which makes a concrete analysis of (also) concrete social situations - thus highlighting the importance of visual/image sources /photographic in the development of historical knowledge.
\end{abstract}

KEYWORDS: Contemporary history. Photography. Iconological analysis. iconographic analysis.

\footnotetext{
${ }^{1}$ Mestranda do Programa de Pós-Graduação em História (UFCG), graduada em História (UFCG) maynarasantos13@gmail.com.

${ }^{2}$ Mestrando do Programa de Pós-Graduação em História (UFCG) e graduado em História (UFCG) pedrodefariasleite@gmail.com
}

Revista Geoconexões Online, v.1, n.1 (2021), 2021. P.36-55. 


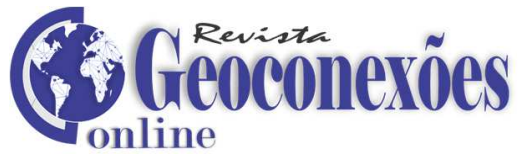

Introdução

O advento da sociedade moderna pode ser considerado, historicamente, o maior impulso cultural e tecnológico que a humanidade já conheceu: o surgimento da maquinofatura, das inovações tecnológicas, o desenvolvimento e aperfeiçoamento técnico dos modos de produzir e reproduzir a vida social possibilitaram que enxerguemos o mundo com outro olhar - literalmente. A fotografia, nesse sentido, surge nesse contexto de renovação econômica que regou o solo da vida cultural e política, haja vista que podemos considerá-la como uma fonte para analisar a realidade histórica e através dela podemos produzir conhecimento sob novas perspectivas. Além disso, a fotografia também conquistou grande popularidade, uma vez que as pessoas queriam registrar suas gerações familiares, assim como também se tornou uma forma bastante utilizada de expressão artística.

Sendo assim, é fundamental pensar na fotografia como parte marcante da modernidade, justamente por ser uma técnica que teve sua gênese nesse período. Nesse sentido, foi uma divisora de águas que trouxe consigo características que continuam a se reproduzir até os dias atuais em nossa sociedade, por meio das tecnologias da informação. Como afirma KOSSOY (2014, p. 46), "é em função dessa multiplicação da informação que a fotografia alcança sua função social maior". Deste modo, é possível afirmar que a fotografia enquanto técnica foi responsável por mudar a dinâmica espaço-temporal da sociedade como um todo, encurtando cada vez mais as distâncias a serem percorridas pela informação:

Invenção burguesa por excelência, a fotografia popularizou ${ }^{3}$ o retrato e levou aos cantos mais distantes do mundo essa "caixa de pandora", contendo paisagens de lugares exóticos, de monumentos, de tipos humanos, retratos com apelos eróticos, paisagens urbanas das metrópoles, imagens chocantes de guerras e de conquistas científicas. (LIMA; CARVALHO; 2009, p. 30).

Entretanto, mesmo explicitamente sendo uma possibilidade de registrar o passado de modo visual, o processo de incorporação das fotografias/imagens à historiografia não foi algo que ocorreu automaticamente, uma vez que a concepção de História dominante do século XIX tinha os documentos escritos (de preferência oficiais) como fonte privilegiada de pesquisa histórica, assim como evidencia-se na "Introdução aos Estudos Históricos" de Charles Victor Langlois, e Charles Seignbos, texto publicado pela primeira vez na França em 1897 no qual

\footnotetext{
${ }^{3}$ Essa popularização se deu pois, ao contrário das antigas classes hegemônicas (nobreza e clero), os burgueses não intencionavam guardar as tecnologias de ponta para si, mas sim transformá-las num produto mercadológico acessível para que pudessem obter a maior margem de lucro possível através de sua comercialização.
} 


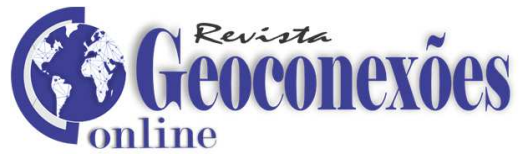

os autores discutem questões metodológicas no que diz respeito ao uso das fontes documentais, pressupondo o total afastamento do pesquisador em relação ao objeto, isto é, o caráter social-subjetivo da historiografia e descartando completamente a necessidade da teoria - uma vez que a objetividade concreta das fontes falaria por si só.

Essa concepção historiográfica, fruto de uma sociedade que tinha uma "paixão especial pela exatidão" (PINSKY; LUCA, p. 30), foi concretamente hegemônica até o fim do século XIX, onde já haviam ocorrido vários processos revolucionários que radicalizaram posicionamentos políticos e medidas econômicas em desenvolvimento, a exemplo da Comuna de Paris de 1871, na qual a classe trabalhadora empreendeu pela primeira vez as bases constitutivas de uma sociedade socialista. Nesse sentido, é de grande influência o próprio desenvolvimento do marxismo enquanto ciência, que não só analisa criticamente a sociedade moderna/capitalista, mas também cria uma nova concepção de história através do materialismo histórico-dialético, uma vez que considera que "os homens fazem sua própria história, mas não a fazem como querem; não a fazem sob circunstâncias de sua escolha e sim sob aquelas com que se defrontam diretamente, legadas e transmitidas pelo passado" (MARX, 1997, p. 21)

Essa forma de interpretação da realidade, apesar de ter-se refletido nitidamente nos processos políticos e ideologicamente no interior desses, só se desdobrou na historiografia a partir do século $X X$, no qual todas as evidências deixadas pela atividade humana sobre a natureza podem ser consideradas como fonte documental para a pesquisa histórica. Com a abertura dos horizontes no que diz respeito às possibilidades de construção do conhecimento histórico, chamamos atenção para o que KOSSOY (2012) denomina como Revolução Documental, em que tanto outros tipos de fonte como a fotografia se tornaram objetos de elaboração teórica e metodológica em relação ao seu uso na historiografia. Assim,

[...]as fontes fotográficas [passaram a ser] uma possibilidade de investigação e descoberta que promete frutos na medida em que se tentar sistematizar suas informações, estabelecer metodologias adequadas de pesquisa e análise para a decifração de seus conteúdos e, por consequência, da realidade que os originou. (KOSSOY, 2012, p. 34)

A ampliação das possibilidades de pesquisa e a grande variedade das fontes, que sofreram uma amplíssima renovação/transformação nos últimos tempos, contribuíram ainda mais para que a fotografia tomasse a atenção de historiadores como uma fonte documental privilegiada, principalmente quando levamos em conta todas as discussões que sistematizam teórica e metodologicamente o uso das fotografias na escrita historiográfica. Os historiadores da contemporaneidade, ao contrário dos do século XIX, já estão bastante habituados com o uso das imagens/fotografias na pesquisa e escrita historiográficas, permitindo que afirmemos 


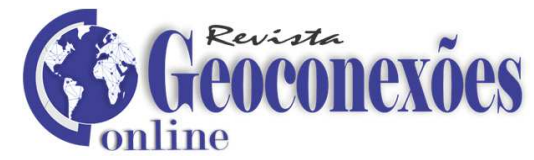

que atualmente entre os profissionais de História é consenso sua legitimidade enquanto fonte documental, uma vez que "o foco sobre a natureza da fotografia desloca-se da relação entre referente e imagem (da ideia de representação como presentificação do ausente) para os mecanismos socialmente estruturados de produção dos sentidos" (LIMA; CARVALHO, p. 43).

\section{Revisão de literatura}

São amplas as discussões que se centram na relação entre fotografia e História: vão desde a visualidade propriamente dita, à cultura imaginária social, o julgamento estético, passando pela sua utilização na produção de discursos, sua versatilidade enquanto fonte documental, até chegar àquelas que refletem acerca de seu caráter epistemológico e sua capacidade metafórica - e um milhão de outras abordagens e perspectivas sobre seu uso. Nesse sentido, é preciso fazer um breve balanço crítico acerca de alguns estudos que se debruçam sobre essa questão e nos quais encontramos referências para desenvolver nossa análise, assim como ficará nítido posteriormente.

A leitura de MAUAD (2016), por exemplo, retoma as discussões já levantadas aqui e nos acrescenta uma reflexão importante: como chegamos ao "ponto de certeza" acerca da capacidade de mobilização que as imagens causam? Desse modo, a autora busca debater como essa questão tornou-se objeto de estudo entre os profissionais de História com o objetivo de estabelecer historicamente a relação entre cultura visual e estudos históricos. Para isso, relembra a renovação historiográfica do fim dos anos 1970 e início dos anos 1980 no contexto brasileiro, que passa a ser mais aberto ao recurso às fontes imagéticas em detrimento da rigidez das fontes escritas - o que, de certa forma, ignora o pioneirismo de figuras como Taunay, considerado "o primeiro profissional de História [brasileiro] a fazer uso intenso das fontes visuais"4 (LIMA; CARVALHO, p. 35).

Além disso, aponta que as discussões mais recentes se voltam para pensar a historicidade da produção de imagens e explicam a influência das imagens na produção de sentidos na historiografia "considerando as suas especificidades históricas como fenômenos socialmente significativos e temporalmente referenciados" (MAUAD, 2016, p. 35), o que descarta completamente a noção metódica da escrita da História, que a autora se refere como "epistemologia da prova". Isso nos leva à discussão acerca do estatuto epistemológico das

\footnotetext{
${ }^{4}$ No entanto, é importante salientar que o pioneirismo de Taunay se ateve ao reconhecimento do potencial pedagógico da imagem. Ou seja, o valor das fontes visuais era sim reconhecido por Taunay, ao contrário de muitos de seus contemporâneos, mas era reconhecido apenas mediante sua subordinação ao texto escrito.
} 


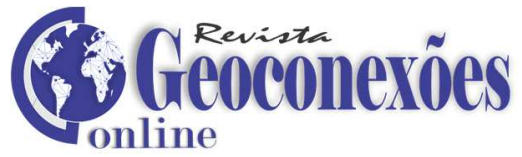

imagens, que pense dialeticamente a relação entre a existência de fontes documentais e práticas sociais historicamente determinadas. Toda a discussão da autora se situa no campo da história cultural, tendo como referência a "virada pictórica" dos anos 1990, proposta por William Mitchell - que, por sua vez, se inspira na noção de "virada linguística" de Richard Rorty, a qual somos críticos por dar vida a muitos "discursos" que destroem as bases da história por dentro ${ }^{5}$, assim como podemos ilustrar com o pensamento de Hayden White em "Meta-História", publicado em 1973.

Ao lembrar que as imagens não têm sentido por si mesmas, MAUAD (2016) mais uma vez rebate a tese de que o documento histórico é fielmente fonte de informação sobre o passado, considerando esta uma concepção reducionista, uma vez que as imagens - assim como qualquer outro tipo de fonte, vale ressaltar - estão vivas na realidade social, tendo em vista que "uma fotografia percorre situações provocadas por sua existência e ação no mundo social, constituindo-se, portanto, como sujeito, objeto e agente da história" (MAUAD, 2016, p. 45). É interessante a provocação lançada pela autora através das reflexões de Lissovsky, que pensa a fotografia como uma "pausa do destino", evidenciando que pode ser considerada tanto uma imagem/documento como uma imagem/monumento, entendendo-se que

No primeiro caso, considera-se a fotografia a marca da materialidade
passada, que nos informa sobre determinados aspectos desse
passado, como condições de vida, moda, infraestrutura urbana ou
rural, condições de trabalho, etc. No segundo caso, a fotografia é um
símbolo, aquilo que, no passado, a sociedade estabeleceu como a
única imagem a ser perenizada para o futuro. Como documento e
monumento, a fotografia informa e também conforma visões de mundo.
(MAUAD, 2016, p. 46)

Atentando para o fato de que geralmente as imagens são utilizadas como meros acessórios ou ilustrações, BURKE (2004) nos chama para pensar no nosso "analfabetismo visual" enquanto profissionais de História. O autor critica, inclusive, o próprio conceito de "fonte", que pressupõe um contato direto com o passado em que os intermédios inexistem, apontando como um conceito mais adequado o de "indícios". É interessante a observação do historiador quando afirma que enquanto profissionais não podemos limitar o uso das imagens como pura "evidência", o que abre margem para que o espectador possa também

\footnotetext{
${ }^{5}$ Todas essas "viradas" se fundamentam na concepção pós-moderna de sociedade, que nasce com o neoliberalismo para justificar a "nova" sociedade e sistema de produção flexíveis, tendo como alguns de seus elementos constitutivos a negação da possibilidade de representação do real (e, no limite, da própria ciência), no relativismo linguístico e cultural, na negação na ideia de progresso e na aceitação indiscriminada de todas as diferenças, "discursos" e pontos de vista possíveis. A nível de informação, podemos atribuir as origens dessa ideologia nas obras de Lyotard, Derrida e Foucault.
} 


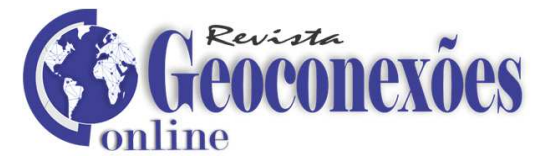

criar/interpretar através das imagens uma vez que elas "nos permitem imaginar o passado de forma mais vívida" (BURKE, 2004, p. 17)

Dessa forma, BURKE (2004) nos convida a refletir acerca do uso de imagens no processo de (re)construção do passado e da realidade social, principalmente no que diz respeito à cultura popular que, quando analisada do ponto de vista do efeito das imagens de publicidade em seu cotidiano, evidencia uma íntima ligação entre a sociedade e as mercadorias no mundo contemporâneo. Assim conclui que, auxiliando-se na psicologia "profunda", a fim de apelar ao inconsciente dos consumidores com o objetivo de incutir implicitamente valores, normas e práticas que, por sua vez, são projetados na nossa cultura de consumo e na sociedade como um todo, o mercado acaba exigindo que os publicitários passem a fazer o uso de técnicas de persuasão por associação, haja vista que

[...]a imagem mental de um produto é construída associando vários objetos com sua imagem visual. Este é um processo de manipulação consciente por parte das agências de publicidade[...], no entanto é largamente inconsciente para os espectadores. Dessa maneira, o carro de esporte, por exemplo, há tempos tem sido associado com poder, agressividade e virilidade[...]. (BURKE, 2004, p. 116-177).

Outra ideia bastante enriquecedora que o autor desenvolve diz respeito ao alcance que a imagem enquanto evidência pode oferecer a um fenômeno/evento histórico comparada a outros tipos de fonte, especialmente pelo seu caráter visual e imediato, uma vez que fontes escritas muitas vezes são elaboradas para leitores já habituados com esse tipo de material e levam muito tempo para ser interpretadas, ao passo que "uma pintura ou uma fotografia muitas vezes é facilmente acessível, especialmente em reproduções, e sua mensagem pode ser esquadrinhada com relativa rapidez". (BURKE, 2004, p. 234). Ele ainda chama atenção para o fato de que na maioria das vezes as imagens não são produzidas deliberadamente como evidências históricas, diferente de documentos escritos. Por isso, evidencia a necessidade de os profissionais de história serem cuidadosos e bastante rigorosos com o uso de imagens, entendendo-se que elas "são muitas vezes ambíguas ou polissêmicas" e, por esse motivo, devem ser entendidas como "visões contemporâneas" (de um mundo passado), colocadas em seu devido "contexto" e observada naquilo que não mostra, isto é, pelas entrelinhas.

Dito isto, salientamos que durante o trabalho com fontes visuais, o historiador tem que estar atento principalmente ao contexto de produção desses documentos e, se possível, traçar um roteiro que estabeleça a trajetória percorrida pelo material desde a sua produção até o seu destino final, pois tendo sido preservado o contexto de produção, o historiador pode ter condições de acessar os relacionamentos responsáveis por gerar um dado documento. $O$ acesso ao contexto de produção assegura ao historiador a confiabilidade da fonte. Cabe ainda 


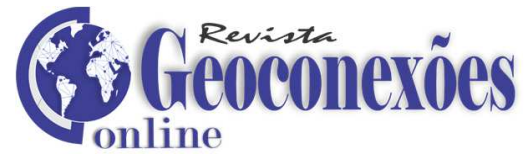

destacar que "a trajetória de consumo da imagem é autônoma de seu referente, das motivações do fotógrafo e da produção". (LIMA; CARVALHO, 2009, p. 46).

Segundo KOSSOY (2012), enquanto fonte documental, a fotografia pode ser entendida como um objeto-imagem levando-se em consideração que ela não consiste em pura representação/registro do passado, fenômeno ou momento histórico específico, uma vez que para existir ela necessita de um suporte técnico-material e, dessa forma, pode indicar e "detectar em sua estrutura as características técnicas típicas da época em que foi produzido". (KOSSOY, 2012, p. 42) Dessa maneira, uma imagem original pode ser considerada uma fonte primária, enquanto as reproduções da original são consideradas fontes secundárias; isso porque as primeiras também são objetos museológicos por conta de seu valor histórico intrínseco, ao passo que as segundas, em função de seu caráter mimético, operam como uma ferramenta de divulgação do conhecimento histórico-cultural.

Sendo um "artefato que contém em si um fragmento determinado da realidade registrado fotograficamente" (KOSSOY, 2012, p. 47), toda fotografia é um resíduo do passado. Nesse sentido, a fotografia representa e é expressão de uma determinada forma de entender e explicar o mundo: basta observar e comparar estudos sobre as mesmas imagens fotográficas no passado e no presente para notar os "filtros culturais" (e histórico-concretos) que marcam tais olhares. O autor ainda indica que existem várias formas de "ler" uma fotografia, tendo em vista que alguns percebem a fotografia por sua pura visualidade ou como ilustrações do texto, à medida que outros buscam olhar para as lacunas, para os detalhes e para coisas que correntemente passariam despercebidas, buscando "transferir e organizar esteticamente essas informações em seus registros" (KOSSOY, 2012, p. 54), o que evidencia a importância das imagens fotográficas enquanto evidência histórica e social, contribuindo para o avanço e aperfeiçoamento da construção do conhecimento no campo das Ciências Humanas.

Após o surgimento das fotografias, além do interesse individual e familiar em fazer registros para a posterioridade, também começou a se delinear um mercado internacional para o consumo de fotos, é a essa sociedade que KOSSOY (2012) denomina "civilização da imagem" e que corresponde a um momento histórico em que a fotografia já aparecia (timidamente) como fonte documental uma vez que o "conhecimento visual do mundo através de imagens se torna moda" (KOSSOY, 2012, p. 146). O modismo possibilita que as imagens passem a ser veiculadas em massa na sociedade pela mídia, passando a operar através de um papel social e político muito bem determinado, principalmente com o surgimento do fotojornalismo, que passa a intervir "moldando - em função da manipulação das imagens/textos - a opinião pública segundo interesses e ideologias (...)"' (KOSSOY, 2012, p. 


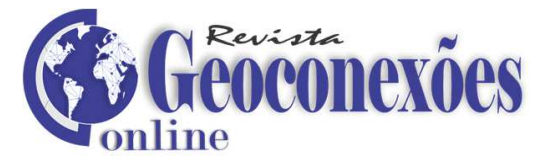

148). Todas essas observações nos servem como exemplo histórico-concreto da validade e legitimidade das fotografias para o conhecimento sobre questões do passado, porém, além do uso profissional de imagens fotográficas, também observamos o impacto que as fotografias tiveram (e continuam tendo) na sociedade.

A fotografia, como vimos, integra muitos setores da vida social urbana. Ela está nas mídias impressas de notícias, no circuito turístico, nas publicações escolares, faz parte da esfera privada, com sua presença nos álbuns que narram a trajetória familiar e cumpre sua vocação documental em inúmeras áreas técnicas e das ciências exatas e biológicas. (LIMA; CARVALHO, 2009, p. 55).

Para o historiador, trabalhar com a fotografia não é mais como nos tempos de seu surgimento, pois as discussões teórico-metodológicas não mais se centram detidamente sobre a legitimidade delas, mas sim em informações sobre sua composição e seu conteúdo social, sendo imprescindível o balanço crítico de seu contexto de produção e dos recursos técnicos de suporte para que se estabeleça a relação existente entre o fato e a foto (que não podem ser confundidos), afastando-se da concepção metódica acerca das fontes documentais, que as considera como puro reflexo/registro da História. Assim,

A fotografia[...] não pode ser o registro puro e simples de uma imanência do objeto: como produto humano, ela cria, também com esses dados luminosos, uma realidade que não existe fora dela, nem antes dela, mas precisamente nela. (KOSSOY, 2012, p. 129)

As fotografias dão sentido ao mundo exterior e são capazes de produzir e reproduzir sentidos, valores e normas que perpassam toda a sociedade e, justamente por esse motivo, as imagens fotográficas só podem ter sentido em sociedade, pois são históricas e sociais, não "falam por si só" nem "revelam" a realidade assim como ela é, já que "a imagem não pode ser entendida apenas como registro mecânico da realidade dita factual" (KOSSOY, 2012, p. 53). A imagem também celebra, protege e nos permite relacionar realidades distintas. Os fotógrafos usam as câmeras como instrumento dessas potencialidades; como instrumentos de mudança. Deste modo, é fundamental compreender a fotografia como "[...] produto humano, ela cria, também com esses dados luminosos, uma realidade que não existe fora dela, nem antes dela, mas precisamente nela. (MACHADO, 1984, p. 40 apud KOSSOY, 2014, p. 59)".

Revista Geoconexões Online, v.1, n.1 (2021), 2021. P.36-55. 


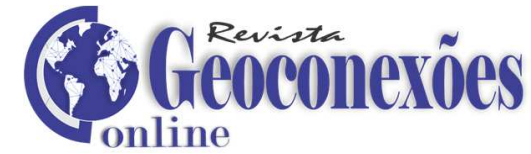

\section{Fontes iconográficas impressas: um convite ao mundo das fontes visuais}

Ao lidar com fontes iconográficas impressas, a pesquisa deve estar focada predominantemente nas questões que concernem ao conteúdo da imagem, já que se trata de uma fonte secundária; uma reprodução. O procedimento é fazer uma inspeção das especificidades do veículo que contém a reprodução (análise técnica), seguidamente da análise iconográfica e iconológica. De acordo com Kossoy (2014, p. 110),

\begin{abstract}
A análise iconográfica, entretanto, situa-se ao nível da descrição, e não da interpretação, como ensinou Panofsky. Este, referindo-se à representação pictórica, revive o velho e bom termo iconologia como um "método de interpretação que advém da síntese mais que da análise" e que seria o plano superior, o da interpretação iconológica do significado intrínseco.
\end{abstract}

Para fim de demonstração dos temas que foram discutidos na introdução, selecionamos fotografias da Feira Central de Campina Grande do ano de 1978, de autoria de Roberto Coura, publicadas em seu livro intitulado "A Feira de Campina Grande” (2007). Esta publicação conta com 90 fotografias - selecionadas pelo autor (dentro de um universo de mais de 1700 imagens obtidas por ele) - das quais selecionamos algumas para análise.

Deste modo, cabe ainda frisar que, enquanto a análise iconográfica diz respeito à identificação do conjunto de elementos que foram captados pela fotografia, a análise iconológica não tem limites, cujo objetivo é confrontar possíveis realidades escondidas 5 por trás da imagem e das inúmeras "manipulações" de toda a natureza que ocorrem ao longo da vida de uma fotografia. Como afirmam Britto \& Corradi (2018, p. 124),

Os registros fotográficos, por sua vez, constituem traços de personalidade de quem registra e/ou preserva as mesmas. O material utilizado nas fotografias e a técnica do fotógrafo são projetadas no resultado final quanto à qualidade e preferências do profissional. Marcas de personalidade são, portanto, representadas nas imagens quando percebemos o ângulo, objetos, cores, foco e sentido que o fotográfico quis apresentar.

Em entrevista ${ }^{6}$ ao Programa Diversidade ${ }^{7}$, Coura revelou que a fotografia de D. Maria (Figura 1) foi escolhida como símbolo atemporal do projeto de documentação da feira livre desenvolvido por ele. Este registro visual é um documento que fala também sobre a história

\footnotetext{
${ }^{6}$ Disponível em: <https://www.youtube.com/watch?v=ZMfvQvGhgsY\&t=260s>. Acesso em: 14 set. 2020.

${ }^{7}$ Exibido de segunda a sexta, às $13 \mathrm{~h} 30 \mathrm{~m}$ e às $18 \mathrm{~h}$, pela TV Itararé de Campina Grande (afiliada da TV Cultura). O programa apresenta reportagens diárias sobre a cultura paraibana, com destaque para 0 que é produzido em Campina Grande e região circunvizinha.
} 


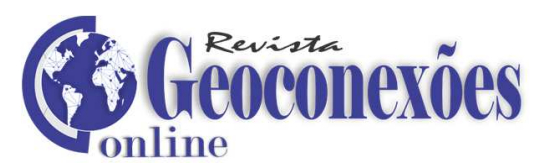

do próprio fotógrafo, que nos momentos de descanso, sentava-se próximo a D. Severina (popularmente conhecida como D. Maria) e passava alguns bons momentos conversando com ela. O resultado do trabalho de Coura é moldado e manipulado de acordo sua trajetória e suas intencionalidades.

$\mathrm{Na}$ apresentação que faz em sua publicação impressa de 2007, Coura relata sobre como foi este longo processo, que levou mais de seis meses:

A cada dia, a cada ida ao meu local de trabalho, a espacialidade imaginária tornava-se concreta. A cada bobina de filme exposto, a vontade louca de correr para o laboratório, para saber se o caminho era mesmo aquele, se estava certo. A preocupação com o social exigia cuidado e rigor expressivo: havia sempre o risco da pieguice, do preconceito.

\section{Fotografia 1: D. Maria (1978)}

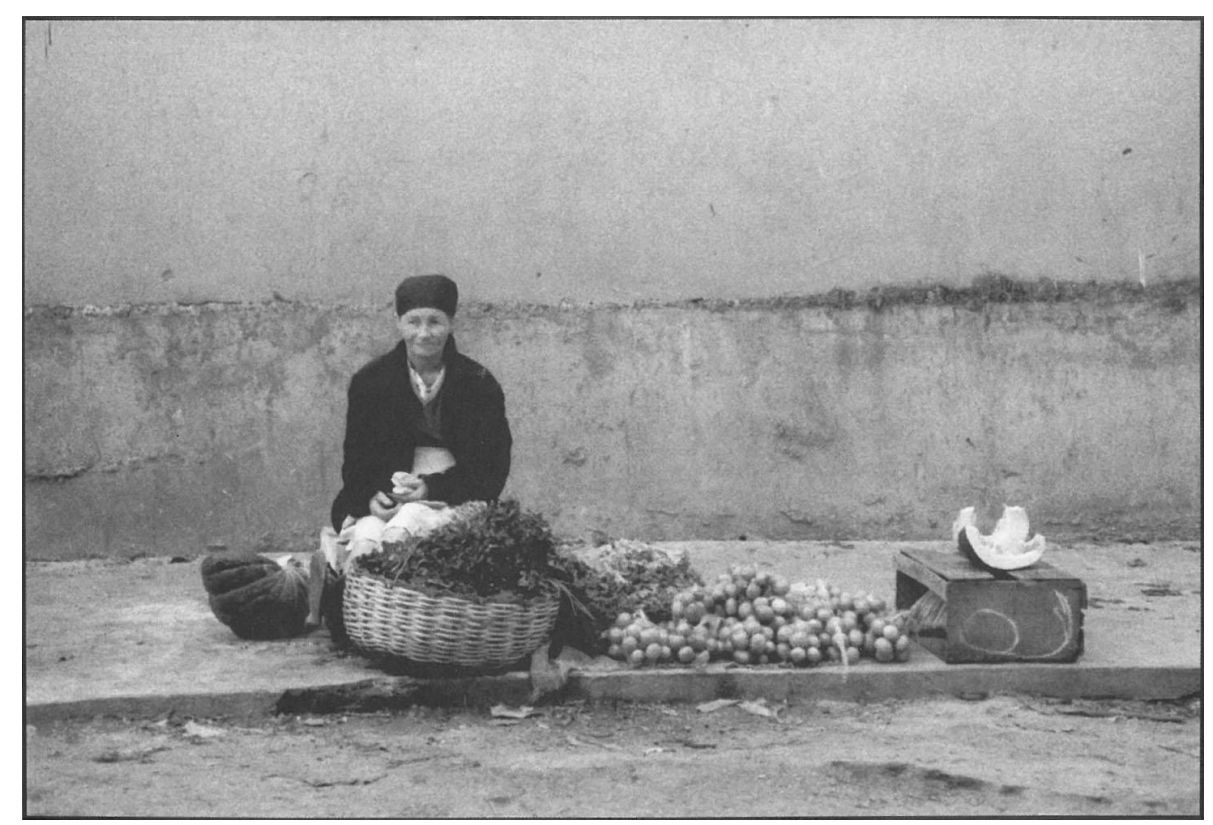

Fonte: Coura (2007).

A primeira edição de seu trabalho foi exposta em 05 de maio de 1979, no Museu de Artes de Campina Grande, e, como relata Coura, os feirantes se fizeram presentes, tanto porque a fotografia apresenta a possibilidade do encantamento, quanto porque Coura também se fez presente no cotidiano da feira. Além da aprovação dos feirantes, tal ensaio obteve o prêmio Marc Ferrez de fotografia. 


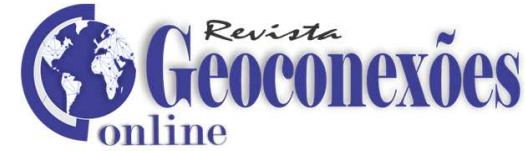

Fotografia 2: Cafezinho (1978)

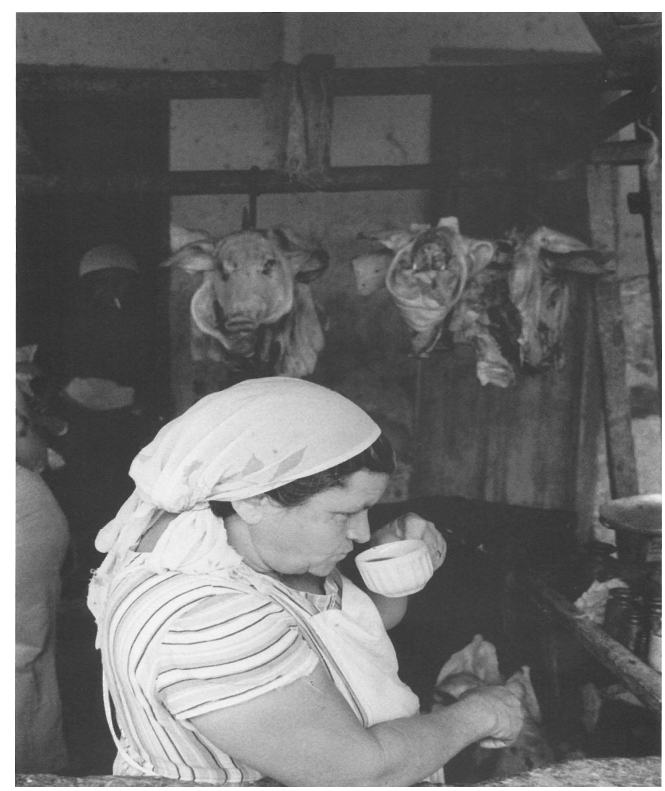

Acervo dos autores

A intenção de Coura com o seu ensaio foi a de transmitir o cotidiano da feira central, enaltecendo-o da forma mais natural possível. Para isso, buscou inserir-se nesse cotidiano com um método voltado para a participatividade, bastante parecido com o usado pelos antropólogos ao estudarem grupos humanos. A "Figura 2" é bastante representativa no que se refere a atitude dos feirantes em relação ao fotógrafo, que em determinados momentos, passaram a não se importar com a presença das lentes.

Sabemos, portanto, que por maior que seja o esforço, o fotógrafo sempre fará um recorte. Uma fotografia não é capaz de abranger uma totalidade, mas um fragmento, escolhido a partir do olhar fotográfico. Da mesma forma que o fotógrafo lança um olhar, posicionado atrás da câmera, os sujeitos que estão sendo fotografados também o lançam, e, desta forma, os olhares se cruzam, concedendo a fotografia mais um elemento encantador. A multiplicidade de olhares presentes nas fotos de Coura, podem ser, sem dúvida, parte de nosso objeto de análise, assim como a displicência da mulher tomando seu cafezinho, rodeada de cabeças de porco; confortável em relação ao lugar ao qual ela definitivamente pertence, pois o lugar também é pertencido por ela.

\section{Imagens da contemporaneidade: a mercantilização dos movimentos sociais}

Ao buscar identificar a relação dialógica entre aparência (progressista) e essência (conservadora) do capital, temos como objetivo desvelar os mecanismos materiais e ideológicos utilizados pelo neoliberalismo para minar por dentro os movimentos sociais 


\section{Gi Gieoconerōes}

através da mercantilização de causas importantes, como o racismo, a LGBTfobia e o machismo. Essa tendência, que se delineia a partir dos anos 70 após a incorporação da luta por direitos que explodiu por todo o mundo na década anterior, é considerada por nós como uma forma do capital se reestruturar e se impor ideologicamente através do pós-modernismo ${ }^{8}$ que, como ideologia oficial, consiste na principal concepção de mundo inclusive no interior da própria esquerda que por sua vez, atualmente também têm mostrado grande compatibilidade com essa lógica de esvaziamento político através da reivindicação de "representatividade", "inclusão", "empoderamento" e "ocupação de espaços".

Dessa forma, as imagens a seguir serão analisadas à luz do materialismo históricodialético, que consideramos a concepção até então mais adequada para analisar tal fenômeno, uma vez que se desenvolve de acordo com a própria dinâmica do sistema de produção capitalista e é capaz de trazer à tona a historicidade e a contradição existentes tanto entre as iniciativas mercadológicas/empresariais que vendem problemas sociais concretos como produtos - que estão assentadas sobre a exploração do homem pelo homem mas aparentemente são concebidas como progressistas porque são "representativas" - como entre os grupos de esquerda - que se afastam de seus objetivos, a saber, de acabar com a dominação - ao aceitar acriticamente as iniciativas do mercado se vendendo por tão pouco o que, além de tudo, contribui ainda mais para a estigmatização da própria militância de esquerda, que no mundo contemporâneo se tornou apenas uma palavra esvaziada de seu verdadeiro sentido.

Nesse sentido, é importante ressaltar que essa tendência de mercantilização é de natureza geral do capitalismo, sendo aprofundada no neoliberalismo que, segundo HARVEY (2008), "se tornou [tão] hegemônico como modalidade de discurso e passou a afetar tão amplamente os modos de pensamento que se incorporou às maneiras cotidianas de muitas pessoas interpretarem, viverem e compreenderem o mundo" (HARVEY, 2008, p. 6). Assim, analisaremos mais especificamente o caso da luta das mulheres, que tem o feminismo como expressão hegemônica, e como foi possível o processo de aproximação com o capital e a consequente incorporação de demandas/pautas que são bastante caras ao movimento.

\footnotetext{
${ }^{8}$ Pois não era necessária apenas uma reestruturação econômico-material, mas também ideológica, que se deu através dessa corrente de pensamento que não pode ser entendida de modo uníssono, tendo em conta que em seu interior existem muitas divergências e até mesmo concepções que se excluem mutuamente. No entanto, mesmo com tanta pluralidade em aparência, essencialmente a ideologia oficial do neoliberalismo tem um fundo social e de classe muito bem determinado, como nos diz HARVEY ao discutir sobre a incorporação que os movimentos sociais sofreram pelo capital, evidenciando a consequente perda do "atrativo de antídoto revolucionário do modernismo para uma ideologia reacionária e tradicionalista". (1992, p. 44)
} 


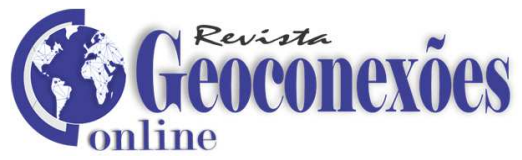

A implantação do neoliberalismo nos anos 70 se deu num momento histórico em que os meios de comunicação modernos já existiam e eram bem disseminados nos grandes centros urbanos em todo globo terrestre: rádio, jornal, TV, cinema, etc. eram, portanto, os principais meios de comunicação em massa pelas quais as empresas faziam propaganda. Os investimentos técnicos e tecnológicos que the sucederam possibilitaram a invenção da internet, o que fez com que as formas de disseminar campanhas de publicidade se complexificassem ainda mais, especialmente nos anos 2000 onde ocorre um acontecimento conhecido como web 2.0, responsável por revolucionar as relações de comunicação e criar novas formas de sociabilidade virtual, caracterizando-se por fazer uso da inteligência coletiva de forma que as pessoas participam tanto como consumidoras como produtoras de informação e de conteúdo, sendo as redes sociais "filhas" deste deslocamento.

Em um mundo que é necessário um incessante estímulo para dar dinamicidade às relações sociais, verificamos a circulação de imagens e representações de fenômenos sociais - das mais variadas ordens - em seu caráter aparente (o que viabiliza uma certa identificação pela estética) em que cada vez mais é possível observar a flutuação e maleabilidade de identidades, que em um mundo "pós-moderno" podem ser manuseadas de acordo com o contexto e vontade dos indivíduos, assim como nos explica HALL (2006) em sua teorização acerca das identidades na cultura da "pós-modernidade", na qual "o sujeito assume identidades diferentes em diferentes momentos, identidades que não são unificadas ao redor de um "eu" coerente" (HALL, 2006. p. 16) Tudo isso torna possível a mercantilização das identidades, uma espécie de "culturalização das mercadorias" que usa estrategicamente diversos tipos de representações e identidades sociais como instrumentos de lucratividade tendência que as campanhas publicitárias de grandes corporações têm nos mostrado nos últimos anos.

Levando em conta que esta tendência que tem a fluidez como regra é de caráter mundial, a adoção de pautas exclusivamente identitárias por parte de certa esquerda acaba legitimando a mercantilização das identidades. Dessa forma, empresas são autorizadas a usar o problema feminino, a questão racial e a causa LGBT explorando todo seu conteúdo identitário vulgarmente e de maneira bastante caricata. É interessante notar a similaridade entre o movimento prático e o teórico, que se complementam numa relação dialógica de sustentação. Um movimento sintomático de um mundo esmigalhado, onde a realidade de privilégio que ocupam os donos das corporações nada tem a ver com a realidade de privação e adoecimento de seus funcionários, pois são apenas "modos de vida" diferentes; em outras palavras, perdeu-se a visão de totalidade, hoje em dia tratada como quimera capciosa e totalizante pelas "modas" acadêmicas hegemônicas. 


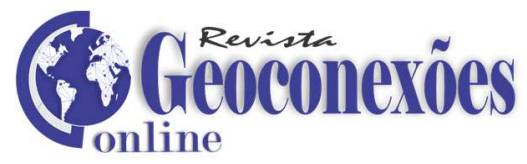

Dessa forma, na contemporaneidade, as redes sociais são uns dos instrumentos de propaganda mais utilizados, inclusive com a criação de "perfis" das empresas para este fim. É assim que podemos explicar a criação do perfil da Magazine Luiza no Instagram, uma das seis redes sociais mais populares do mundo (vide nota 7), que na imagem abaixo (Printscreen 1) faz uma publicação com mais de 70 mil "curtidas" sobre a Consciência Negra em que sua personagem, a Magalu, está lendo/divulgando autoras negras - como Djamila Ribeiro e Carolina Maria de Jesus - para "conhecer novos pontos de vista" em livros vendidos pela própria empresa. Entre tantos elementos questionáveis, como por exemplo o fato de uma empresa estar preocupada (em vender?) com a Consciência Negra (vide nota 8), gostaríamos sinceramente de saber ao que se refere a empresa quando fala sobre "novos pontos de vista e diferentes perspectivas" pois, se levadas ao fim e ao cabo, estas divergem absolutamente da existência própria da forma capitalista de acumulação e produção/reprodução da vida social, que é justamente a única forma que a Magazine Luiza tem de existir.

É assim que podemos explicar a criação do perfil da Magazine Luiza no Instagram, uma das seis redes sociais mais populares do mundo ${ }^{9}$, que na imagem abaixo (Printscreen 1) faz uma publicação com mais de 70 mil "curtidas" sobre a Consciência Negra em que sua personagem, a Magalu, está lendo/divulgando autoras negras - como Djamila Ribeiro e Carolina Maria de Jesus - para "conhecer novos pontos de vista" em livros vendidos pela própria empresa. Entre tantos elementos questionáveis, como por exemplo o fato de uma empresa estar preocupada (em vender?) com a Consciência Negra ${ }^{10}$, gostaríamos sinceramente de saber ao que se refere a empresa quando fala sobre "novos pontos de vista e diferentes perspectivas" pois, se levadas ao fim e ao cabo, estas divergem absolutamente da existência própria da forma capitalista de acumulação e produção/reprodução da vida social, que é justamente a única forma que a Magazine Luiza tem de existir.

Num mundo que precisa das imagens para se reproduzir ${ }^{11}$, aparentar ser antirracista se tornou moda. E moda, além de vender, instrumentaliza esteticamente quase tudo - até

\footnotetext{
${ }^{9}$ Acesso em 27 de março de 2012. Disponível em <https://www.maioresemelhores.com/maiores-redessociais-do-mundo/>.

${ }_{10}$ Uma vez que o racismo nasce como um elemento ideológico necessário ao desenvolvimento do capitalismo no hemisfério Sul, especialmente em função do tráfico negreiro, empregado para suprir demanda de trabalho necessário à acumulação de capital. Mais em MOURA, Clóvis. Escravismo, colonialismo, imperialismo e racismo. Afro-Ásia, o 14, Salvador, 1983. e MOURA, Clóvis. O racismo como arma ideológica de dominação. Revista Princípios, São Paulo, oㅜ 34, ago./out. de 1994.

11 Segundo HARVEY, a "pós-modernidade", isto é, a condição histórico-geográfica da sociedade contemporânea exige que o capital crie um "sistema de espelhos", que fetichize esteticamente tudo ao seu redor e transforme em mercadoria - como é o caso do feminismo que analisamos. Nesse sentido, as tendências da moda inclusas nas propagandas que temos acessos por meio de imagens, fazem parte de uma lógica de "produção cultural e formação de juízos estéticos mediante um sistema
} 


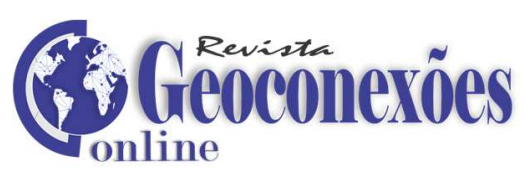

mesmo lutas radicais como a de Carolina Maria de Jesus ${ }^{12}$. Por isso, é preciso resgatar historicamente os maiores nomes e principais experiências da luta antirracista no Brasil e no mundo se quisermos, de fato, promover uma consequente conscientização acerca das mazelas sociais, econômicas, históricas e políticas que o racismo abriu na sociedade brasileira, e não será através de nenhuma empresa que isso vai acontecer, principalmente sabendo-se que a contradição principal do capitalismo é o antagonismo de classe, que coloca os meios de produzir na posse de pouquíssimos e socializa o trabalho àqueles que nada possuem além de sua força de trabalho para ser explorada se quiserem satisfazer suas necessidades básicas, que são genuinamente humanas - como comer, beber e morar.

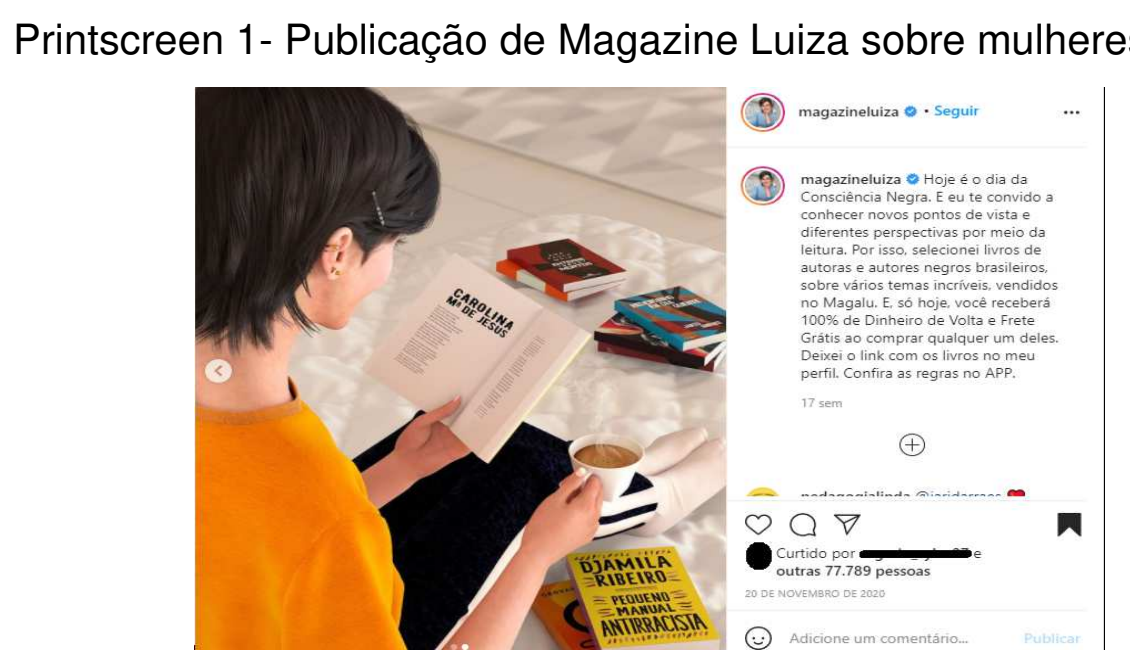

Acesso em 26 de março de 2021. Disponível em <https://www.instagram.com/p/CH0CZenJbx5/>

Certamente, se algum ser mortal ir até uma das lojas da rede empresarial da Magazine Luiza aceitando o "convite" a "conhecer novos pontos de vista e diferentes perspectivas por meio da leitura" mas não tiver dinheiro para adquirir tais conhecimentos, o antirracismo da empresa vai por água abaixo. Analisando a composição visual da imagem e elencando-os às intenções lucrativas da empresa, reveladas em sua contradição, é nítido que como historiadores ainda precisamos aprofundar muito as pesquisas sobre os usos das

organizado de produção e de consumo mediado por divisões do trabalho, exercícios promocionais e arranjos de marketing sofisticados". (1992, p. 311)

12 Que em vida lutou cotidianamente contra a crueza da fome e enfrentou os males de ser uma mulher pobre, preta e periférica, tendo sido reconhecida publicamente só de maneira póstuma. Já a outra autora que a propaganda mostra, Djamila Ribeiro, é um pouco mais problemática, sabendo-se que mesmo sendo porta-voz do Feminismo Negro no Brasil já flertou explicitamente com campanhas empresariais como as da Avon, para qual vendeu sua imagem de mulher "empoderada" - o que é uma questão importante de se discutir, uma vez que nem os vínculos empregatícios das "executivas de venda" a Avon concede às mulheres que fazem as engrenagens da empresa girar, em especial de mulheres negras, que são maioria no mercado informal brasileiro e as quais Djamila visa representar. 


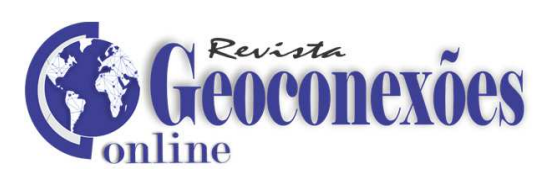

propagandas na historiografia, haja vista que "o estudo da apropriação da imagem é um desafio ao historiador interessado em mobilizar fontes visuais em suas pesquisas". (LIMA; CARVALHO, 2009, p. 46)

Printscreen 2 - Publicação de Magazine Luiza sobre violência contra a mulher

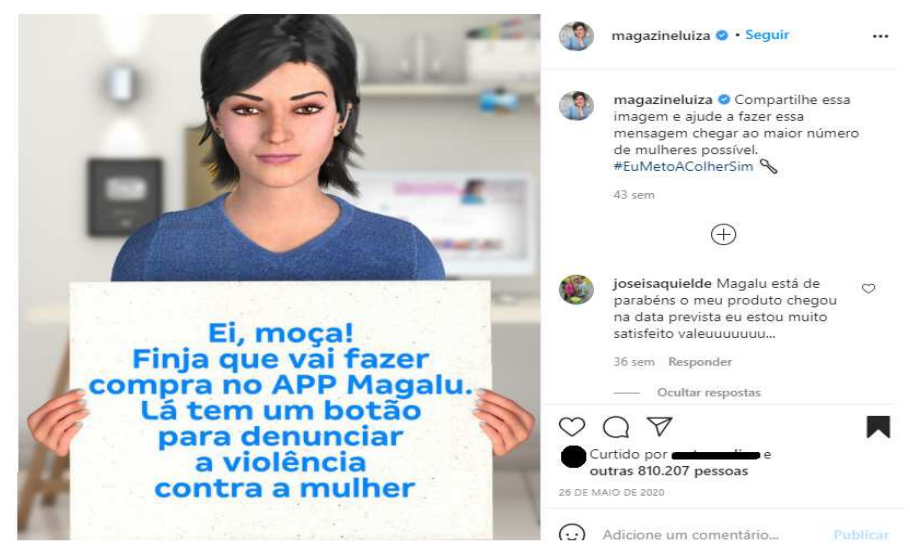

Acesso em 26 de março de 2021. Disponível em <https://www.instagram.com/p/CAqhH Gg327/>

A imagem acima (Printscreen 2) também nos chamou muita atenção por três motivos: 1) pela nítida contradição de uma empresa se solidarizar com a situação das mulheres na sociedade de classes, uma vez que o desemprego estrutural faz parte da própria lógica da economia capitalista e são as mulheres ${ }^{13}$ o grupo social mais atingido pelo desemprego, pela precarização e que ocupa os cargos de menor qualificação no mercado de trabalho ${ }^{14}$; 2) pela denúncia à violência contra a mulher, como se a questão da violência se limitasse aos maus tratos físicos e não também aos psicológicos, subjetivos, que são formas dominantes na exploração do trabalho da qual todas as empresas são dependentes e que castram a potencialidade individual e roubam o tempo do trabalhador (e neste caso, a mulher trabalhadora) ${ }^{15}$; e 3) pela idealização do alcance das redes sociais na sociedade brasileira, sabendo-se que apesar de um forte instrumento de propaganda, a internet não é acessível a

\footnotetext{
${ }^{13}$ Segundo dados do Pnad de 2015, as mulheres recebem $76,1 \%$ dos rendimentos do trabalho masculino no exercício da mesma função. A mesma pesquisa ainda indica que o número de mulheres em condição de desemprego é de $11,7 \%$ contra $7,9 \%$ da população masculina. Disponível em $<$ https://biblioteca.ibge.gov.br/visualizacao/livros/liv98887.pdf> Acesso em 27 de março de 2021.

${ }^{14}$ Como diz SAFFIOTI, antes de mais nada, a ausência global de qualificação feminina funciona como um pilar estrutural do sistema capitalista, tendo em vista que "a marginalização de grandes contingentes femininos do sistema dominante de produção de bens e serviços transforma-os em força de trabalho potencial para esse sistema, portanto, em reguladores dos salários da mão de obra efetivamente nele empregada". (1975, p. 132)

${ }_{15}$ Que tem ainda mais limitações na sociedade de classes uma vez que além de menos capacitada, ocupa um lugar de inferioridade nas estruturas de dominação social em relação aos homens de sua classe, além de ser responsável por uma dupla ou tripla jornada de trabalho.
} 


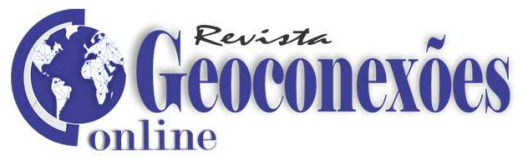

pelo menos 46 milhões dos brasileiros ${ }^{16}$ - e por isso não são os únicos meios de comunicação que as empresas usam para divulgar suas campanhas de publicidade, tendo em conta que os meios tradicionais de massa como a TV e o rádio ainda são bastante utilizados com este fim.

Ainda assim, é interessante notar as "curtidas" da publicação, que chegam a ultrapassar a marca de 200 mil, o que evidencia - em partes - a aceitação acrítica e quão hegemônica essa prática já está popularizada na sociedade brasileira. No caso da empresa em questão, apesar da necessidade de desvelar sentidos, as imagens têm um grande conteúdo didático acerca da realidade social em que os movimentos sociais estão inseridos atualmente, além dos riscos enfrentados pela esquerda com a estetização e mercantilização das lutas sociais. Nesse sentido, vale lembrar as observações de KOSSOY (2012) que se aplicam às imagens analisadas aqui, "'produzidas' segundo técnicas de persuasão que visam, em última análise, levar o homem ao consumo" (p. 148), uma vez que

\begin{abstract}
A indústria da imagem se viu enormemente desenvolvida em função da sociedade de consumo; e a publicidade, estabelecendo padrões de gosto e comportamento, tem desempenhado papel preponderante na criação de todo um ideário estético. (p. 148-149)
\end{abstract}

Nesse sentido, podemos ver que para a análise da nossa realidade histórica no que diz respeito às lutas que enfrentam os movimentos sociais, as imagens de campanhas publicitárias podem auxiliar os profissionais de História a entender e explicar as contradições da lógica de produção capitalista tanto em sua dimensão material - desvelando o caráter de classe que divide o trabalho e, portanto, separa os homens em proprietários e despossuídos - como seus elementos ideológicos - evidenciando como a ideologia pós-moderna dominou a produção cultural, a moda e os movimentos sociais através da [pretensa] fragmentação de um mundo cada vez mais globalmente unificado. Nessas condições de mercantilização, fetichização e estetização da própria radicalidade que - ainda - resiste nos movimentos sociais e, aqui em especial, no feminismo, a esquerda precisa resgatar suas lutas contra a opressão histórica das mulheres e demonstrar que a resposta contra o machismo e toda estrutura de dominação e exploração que coloca as mulheres em posição de inferioridade não veio e não virá do capitalismo - que cobra um preço alto pelas migalhas que oferece.

\footnotetext{
${ }^{16}$ Acesso em 27 de março de 2021. Disponível em $<$ https://g1.globo.com/economia/tecnologia/noticia/2020/04/29/em-2018-quase-46-milhoes-debrasileiros-ainda-nao-tinham-acesso-a-internet-aponta-ibge.ghtml>.
} 


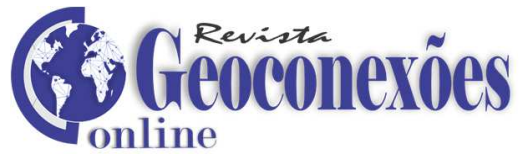

\section{Considerações finais}

Através deste artigo, buscamos evidenciar diferentes possibilidades para 0 desdobramento de pesquisas utilizando as fontes visuais, tendo como objetivo principal o fortalecimento de uma área que já é promissora na historiografia, mas que ainda está em processo de refinamento. Também neste sentido, decidimos abordar o uso das fontes visuais digitais, que ainda não se encontram no rol de tipos de fontes mais utilizadas pelos historiadores e que são motivos de algumas controvérsias em relação à autenticidade enquanto fonte documental - o que evidencia o longo caminho que os historiadores do presente têm pela frente para enfrentar para a construção de um conhecimento histórico que faça jus às complexidades de sua condição histórico-concreta.

A modernidade, por sua vez, pode ser explicada didaticamente a partir do advento da máquina fotográfica, já que a reprodução de imagens cresceu exponencialmente desde então, possibilitando o alargamento do contexto espacial na medida em que encurta o tempo especialmente na "pós-modernidade", onde é possível a troca de informações e imagens sobre contextos muito diferentes em tempo real, o que intensifica profundamente a compressão do espaço pelo tempo, ainda segundo a concepção de Harvey [acrescentar nota]. Uma das características da modernidade é a supressão do sujeito. Descrevendo o sistema capitalista moderno e digital, Canclini (2005) denota que "[...] é cada vez mais difícil encontrar um fabricante que venda o produto e até mesmo o empregado que o vendeu [...]" (p.184) a fim de demonstrar como as individualidades estão dilaceradas sob a imposição de um padrão externo cada vez mais hegemônico.

A fotografia é um produto da modernidade e vice-versa, é uma relação simbiótica e que se confunde, uma vez que faz parte do cotidiano social e informa sobre essa realidade através de seu registro imagético, deixando questões sobre seu contexto de produção, assim como sobre seus possíveis interesses e significados. Dessa maneira, somos levados a refletir acerca da presença da fotografia em todos os setores da sociedade, e consequentemente de nossas vidas. Isso vem sendo uma constante durante todo o processo de modernização. Portanto, os historiadores, sociólogos, filósofos e demais profissionais da área de humanas devem estudar o impacto que a prática de reproduzir, compartilhar, vender e consumir fotografias tem em nossa sociedade - especialmente numa lógica de produção e reprodução das relações que é intensamente marcada pela presença e incessante circulação de imagens.

A realização deste artigo possibilitou a demonstração do uso de fontes visuais em duas formas distintas (respectivamente, tópicos I e II). Em ambos os casos, a imagem enquanto 


\section{G3 Giecoconerexóes}

fonte demonstrou ser um eficaz ponto de partida na construção do conhecimento acerca de determinados contextos históricos e explorar as contradições e complexidades que os envolve, dando riqueza ao debate à medida que cumpre sua função histórica e historiográfica nos informando não apenas seu conteúdo imagético, mas também ao possibilitar apontar marcas da sociedade que a produziu, que lhe consome e que the preservou - o que permite ao historiador enxergar certas regularidades no processo sócio-histórico e identificar práticas e valores sociais específicos e que dizem respeito ao nosso papel social enquanto profissionais de história.

Assim como o peso e o mérito das historiadoras e dos historiadores em reconstituir experiências do passado para entendê-las segundo o presente, a fotografia também faz parte de algo que foi mas já não o é mais: a imagem congelada de um momento que só pode ser (re)vivido pela imaginação - o que não deixa de ter implicações muito palpáveis na realidade concreta. Ainda para retomar KOSSOY (2012, p. 56) sobre o impacto e magnitude desse tipo de fonte documental, "a fotografia é uma imagem que se forma numa intersecção singular de espaço e tempo".

Assim sendo, ressaltamos a necessidade e a importância do uso de imagens enquanto fonte documental (não apenas de maneira secundária/complementar) para a reconstituição do passado e da realidade assim como à construção do conhecimento histórico/historiográfico, de modo que possamos conhecer a nós próprios e deixar nossas marcas para que os profissionais de história do futuro (se é que em história podemos falar em futuro) possam não só entender a si mesmos e nos interpretar, como saber o que nós sabíamos sobre nós mesmos e deliberadamente escolhemos registrar - uma vez que a imagem "é também expressão de um ponto de vista" (KOSSOY, 2012, p. 54).

\section{Referências}

BRITTO, Augusto César Luiz; CORRADI, Ana Laura. Ego-Documentos: Os Documentos Que Expressam A Personalidade, Intimidade E Motivações Dos Titulares De Arquivos Pessoais. In: Biblos: Revista Do Instituto De Ciências Humanas E Da Informação. V. 32, N. 2, Jul./Dez, 2018, P.P. 98-129. Https://Doi.Org/10.14295/Biblos.V32i2.7968

BURKE, Peter. Testemunha Ocular: História E Imagem. Bauru, SP: EDUSC, 2004.

CANCLINI, Néstor García. Diferentes, Desiguais E Desconectados: Mapas Da Interculturalidade. Trad. Luiz Sérgio Henriques. Rio De Janeiro: UFRJ, 2005. 283p.

COURA, Roberto. A Feira De Campina Grande. Campina Grande: Editora Universitária/UFCG, 2007.

HALL, Stuart. A Identidade Cultural Da Pós-Modernidade. São Paulo: DP\&A, 2006. 


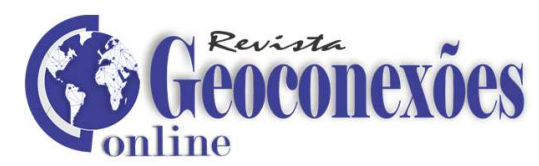

HARVEY, David. O Neoliberalismo: História E Implicações. São Paulo: Edições Loyola, 2008.

HARVEY, David. A Condição Pós-Moderna. São Paulo: Edições Loyola, 1992.

OSSOY, Boris. Fotografia E História. 4를. São Paulo: Ateliê Editorial, 2012.

LANGLOIS, C. V.; SEIGNOBOS, C. Introdução Aos Estudos Históricos. Trad. Laerte De Almeida Morais. São Paulo: Editora Renascença, 1946.

LIMA, Solange Ferraz De; CARVALHO, Vânia Carneiro De. Fotografias: Usos Sociais E

Historiográficos In. PINSKY, Carla Bassanezi; LUCA, Tania Regina De (Orgs.). O Historiador E Suas Fontes. São Paulo: Contexto, 2009.

MAUAD, Ana Maria. Sobre As Imagens Na História: Um Balanço De Conceitos E Perspectivas. Revista Maracanan, Vol. 12, № 14, P. 33-48 Jan./Jun. De 2016.

Https://Doi.Org/10.12957/Revmar.2016.20858

MARX, Karl. 018 Brumário. 7ª Ed. Rio De Janeiro: Paz E Terra, 1997.

PINSKY, Carla Bassanezi; LUCA, Tania Regina De (Orgs.). O Historiador E Suas Fontes. São Paulo: Contexto, 2009. 